\title{
قراءة نقدية لآراء ابن رشد الفلسفية - نظرية النفس أنموذجًا -
}

\section{أ.م.د. اياد كر يم الصلاهي} جامعة واسط / كلية الآداب

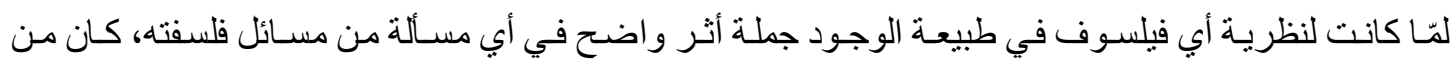
الطبيعي أن يكون لطابع الوحدة الذي تنطبع بـه فلسفة إبن رشد ولنزعته الخاصـة نحو ((وحدة الوجود)) و ((وحدة العقل))

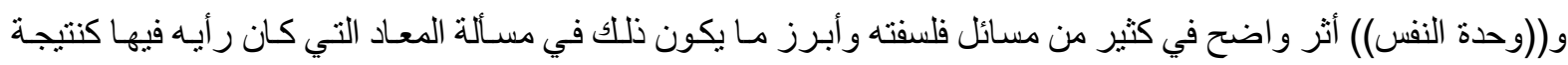

لر أيه في وحدة العقل خاصة.

فقد قال ابن رشد بوحدة العقل وعمومه في هذا الوجود، وإن العقل نوعان:

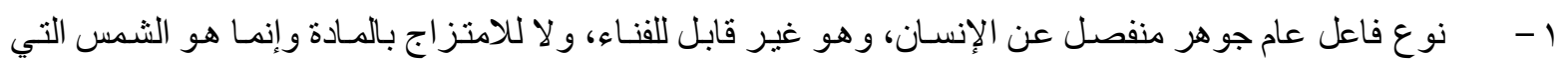

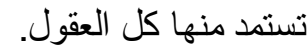

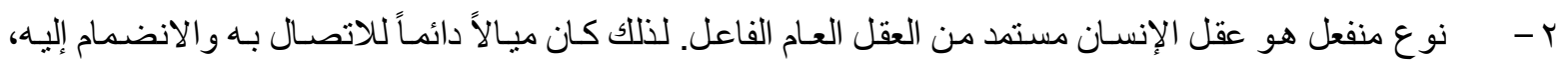
لهذا كانت نفس الإنسان في نزو ع دائم وشوق مستمر إلى الباري ( ').

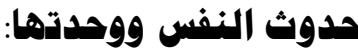

إن مشكلة حدوث النفس من المشكلات العويصة في فكر ابن رشد، و التي تعامل معها بحنكة شديدة وعالجها في إطار فلسفي قلما نجده عند غيره من المشائين، وقد يخيل للباحث في فلسفة إبن رشد المستقاة من كتبه، أنه لم يُعن بعلاج

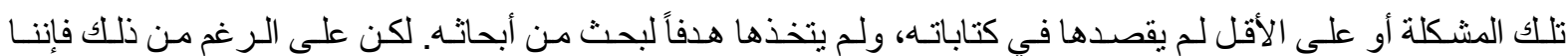

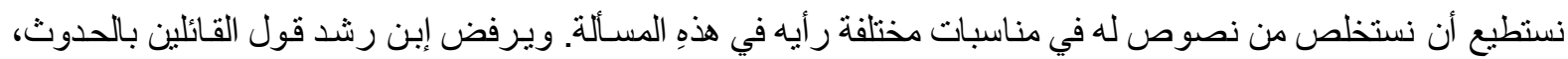
فيقول: ((لا أعلم أحد من الحكماء قال أن النفس حادثة حدوثاً حقيقياً ثم قـال إنها باقيـة إلاّ مـا حكاه (يقصد الغز الي) عن إبن

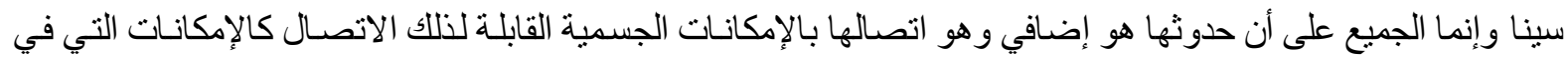
المر ايا لاتصال شعاع الثمس بها وهذا الإمكان عندهم لبس هو من طبيعة إمكان الصور الحادثة الفاسدة، بل هو إمكان على نحو ما يزعمون أن البرهان أدى إليه، وأن الحامل لهذا طبيعة غير طبيعة الهيولى)( (؟). إذن فـابن رشــ يـرفض القول بالحدوث الحقيقي محتجـاً بـالقول بـأن جميع الفلاسفة (الحكمــاء) قـالوا بالحدوث الإضافي. والحدوث الإضافي ((هو الذي مضى من وجوده شيء أقل مما مضى من وجود شيء آخر)) (َّ). يقر إبن رشد بمبدأ وحدة النفس، أب أن النفس واحدة وأن ليس هنـاك نفوس متعددة، ويبر هن على ذلك بـالقول

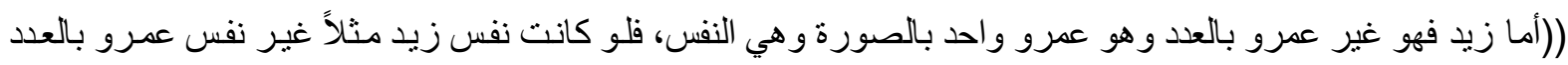

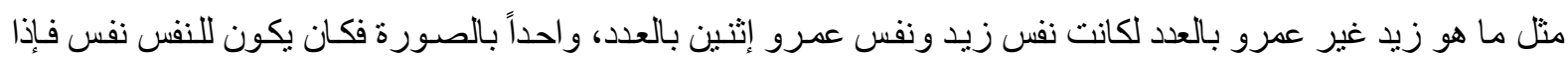

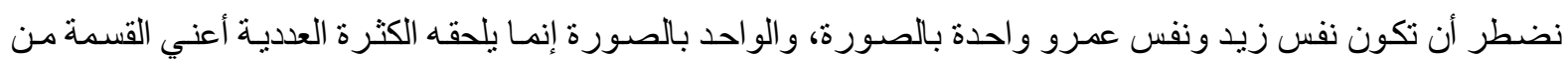
قبل المو اد فإن كانت النفس ليست تهلك إذا هلك البدن أو كان فيها شيء بهذهِ الصفة فو اجب إذا فارقت الأبدان أن تكون

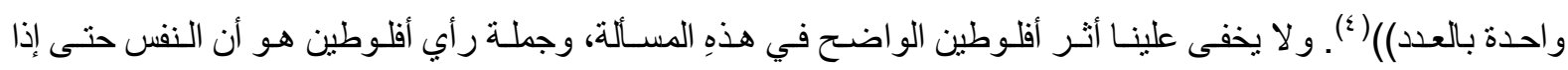

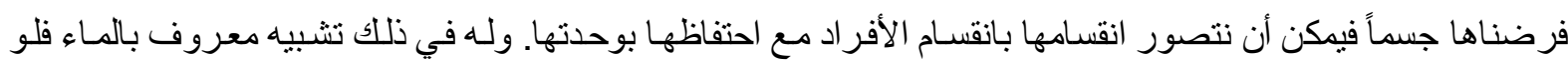
قسمنا مقدارً من المساء إلى عدة مقادير كان كل مقدار جوهر أ، وتتخـالف هذهِ الجواهر لأن كل منها يشكل حيزاً مختلفاً، 
ولكنها مع ذلك كلها من طبيعة واحدة لأنها جميعاً ماء وتحمل جميعها صورة المـاء، أو نوع المـاء، هذِِ هي صورة النفس الإنسانية التي تظل واحدة مع تعدد الأفراد (0).

لكن هل القول بوحدة النفس يعني أنها قديمة؛ لا يوجد نص صريح لابن رشد يقول فيه بقدم النفس، ورغم نلك يمكننا القول بأن النفس عنده قديمة وذلك بناءً على رفضه فكرة الأنفس الجزئية لأن الله تعالى عندما نفخ في الإنسان نفساً

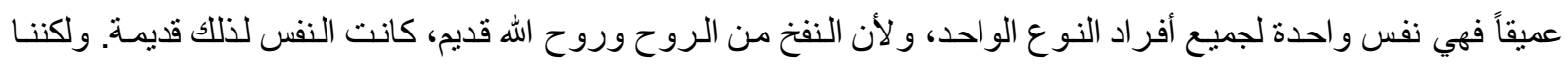

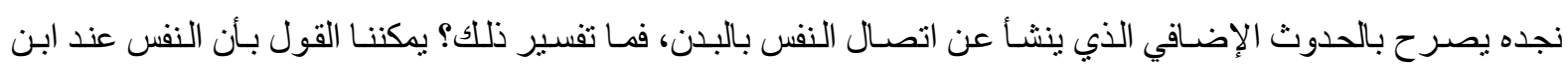

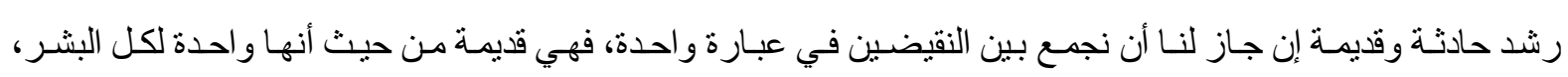

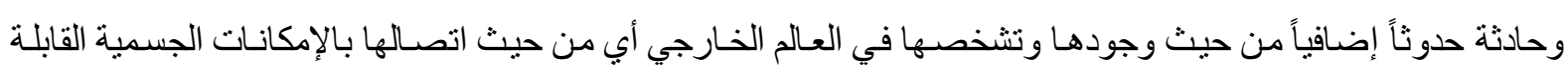

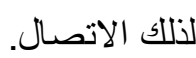

هنا يبرز سؤ ال يفرض نفسه: إذا كانت النفس الإنسانية واحدة وغير منقسمة بانقسـام الأشخاص و أنه لبس هنـاك

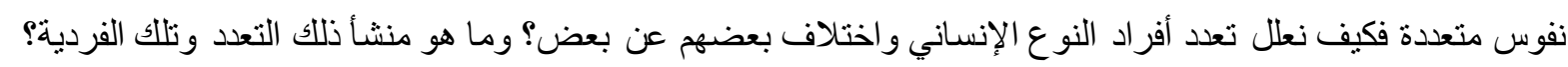
نجد أن إبن رشد يذهب إلى القول بـأن الفرديـة ناشئة عن البدن ((فنفس زيد وعمرو هي واحدة من جهة، كثيرة

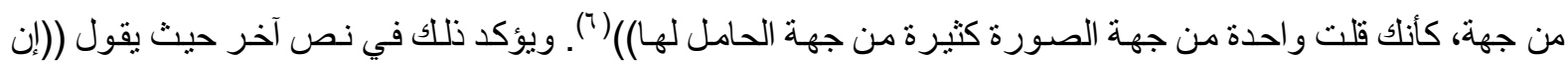

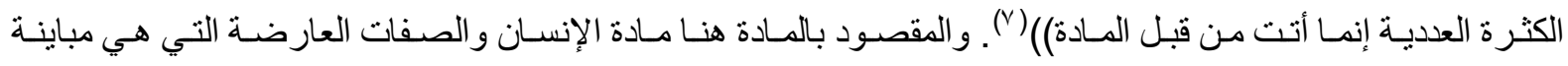

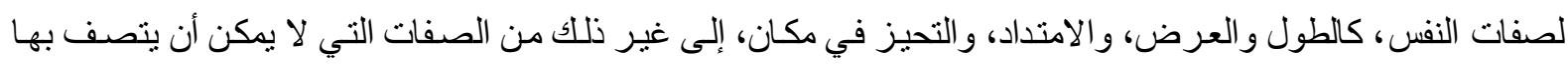

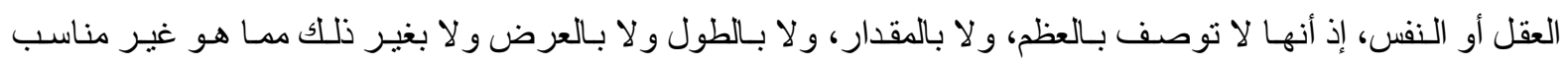
لطبيعتها ومتنافر مع جوهر ها.

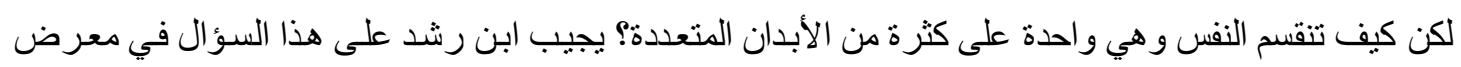

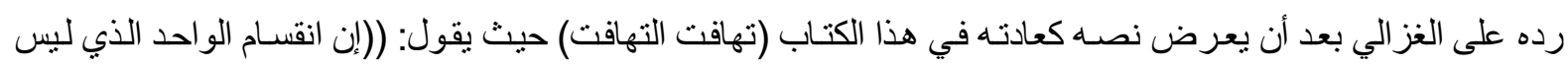

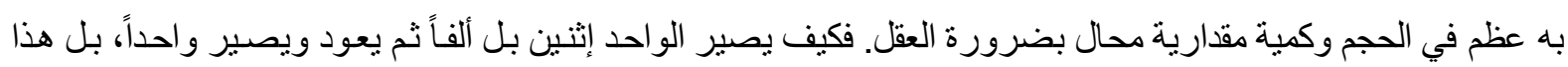
يعقل فيما له عظم وكمية كماء البحر ينقسم بالجداول والأنهار ثم يعود على البحر فأما ما لا كمية له فكيف ينقسم (^). يرد ابن رشد على الغزالي رداً في غاية الوضوح فائلاً: (وأما قوله (الغز الي) أنه لا يتصور إلا فيمـا كمية فقول

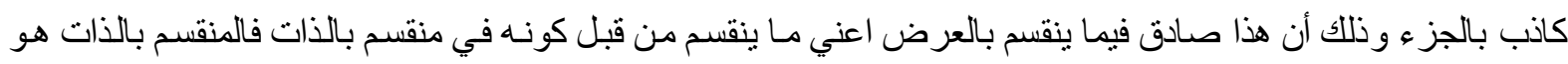

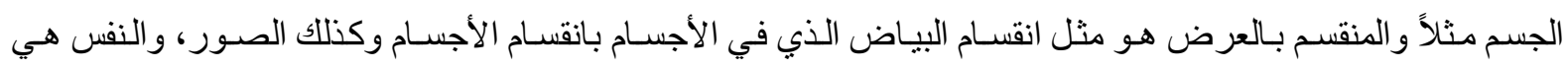

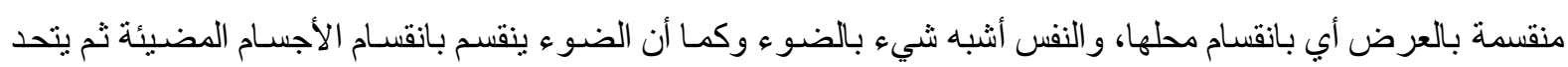

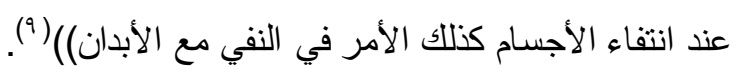
نلخص من هذا كله إن النفس عند ابن رشد قديمة وإن قال بالحدوث الإضـافي في القائم على العلاقة الطارئة بين

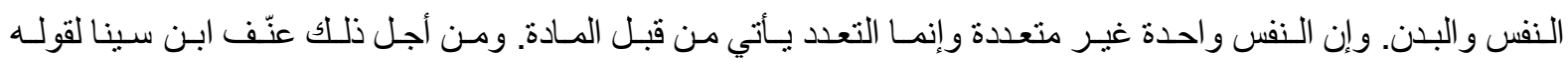
بالحدوث وتعدد الأنفس.

\section{الصلة بين النفس والبدن:}

يرى ابن رشد أنه رغم الاختلاف القائم بين طبيعتهمـا فإن النفس تتصل بالبدن وليس هذا الاتصـال جو هريـاً ولا

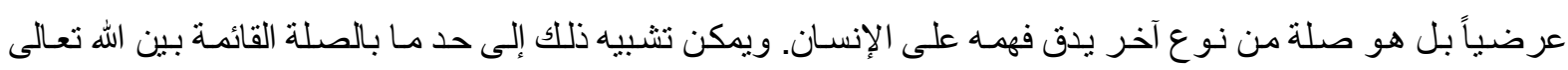




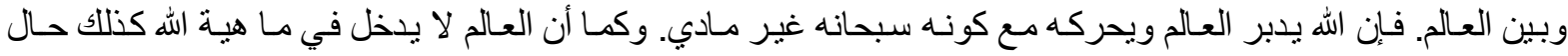
البنن مع النفس.

وقد وافق ابن رشـ مـا ذهب إليهه الغز الي من ان الإنسـان يشـعر بنفسه ولكنه لا يستطيع أن يحدد لها مكاناً في

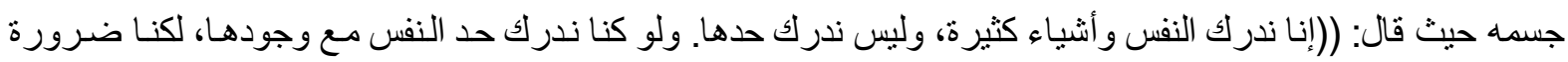

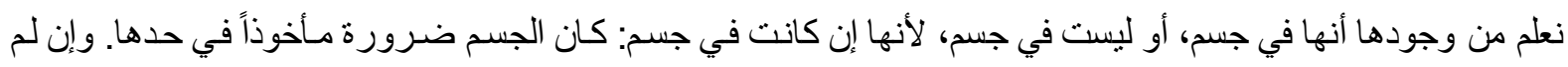

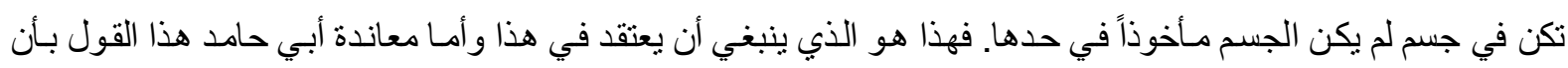

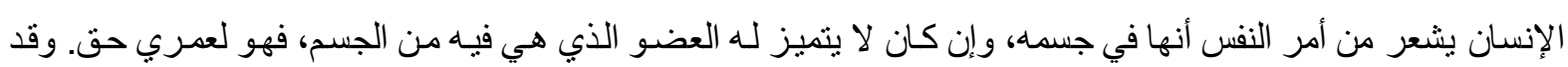

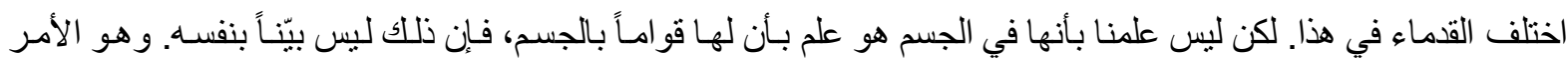

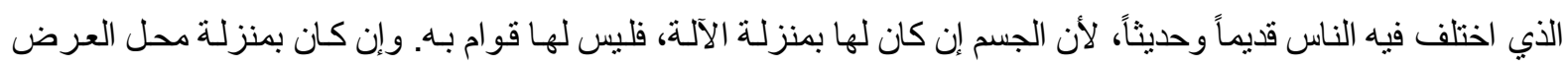
اللعرض لم يكن لها وجود إلآ بالجسم)( · (').

مسألة المعساد مـن المشكلات العويصـة في فكر ابن رشـ و التـي دار حولها الكثير من النقاش و الجدال من قبل

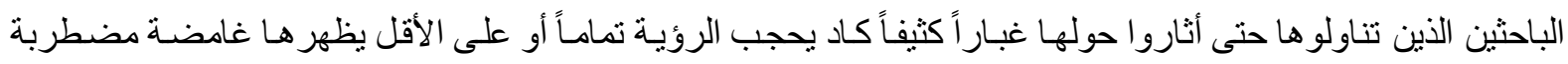

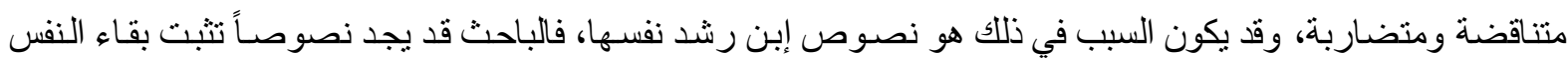
وخلودها. ويجد أخرى قد نؤول إلى القول بفسادها وفنائها. مما دفع بعض الباحثين إلى تعليق البت في تللك المشكلة وعدم

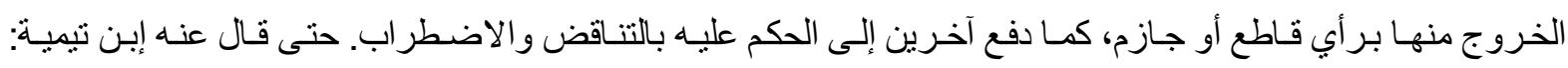

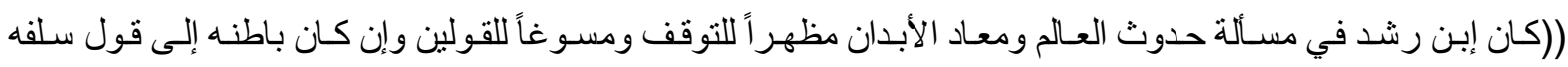

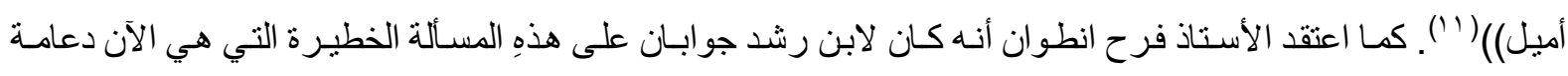

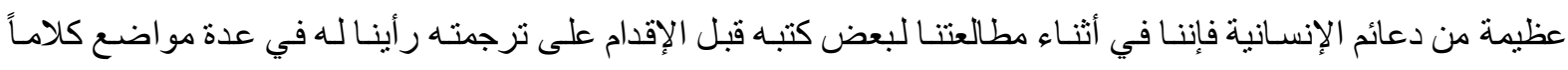

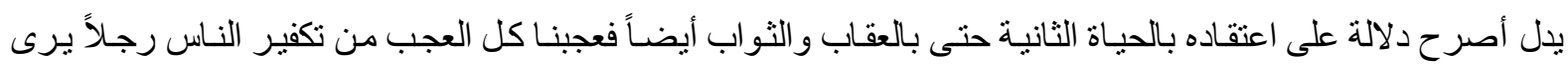

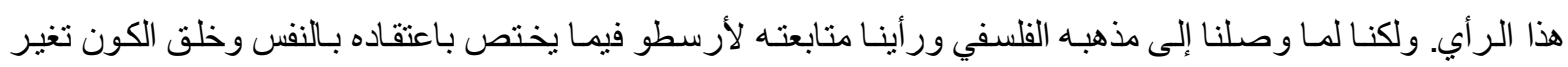

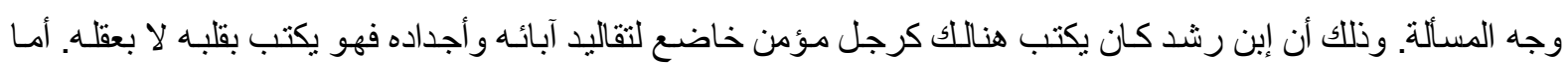

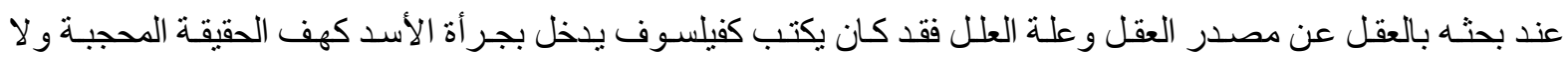
ييالي (r'). وتذهب د. زينب الخضيري إلى مثل نلك الرأي فتقول: أنه كان في كتبه الفلسفية يلتزم بالأدلة البر هانية، وبمـا

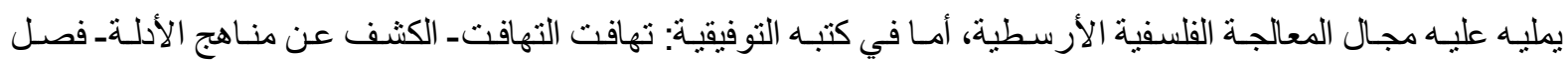
المقال فكان يتحكم في تفكيره فيها محاو لته التوفيق بين آرائه وبين الدين. وبعبارة أخرى يقول أنه كان يحاول ألا يصطدم

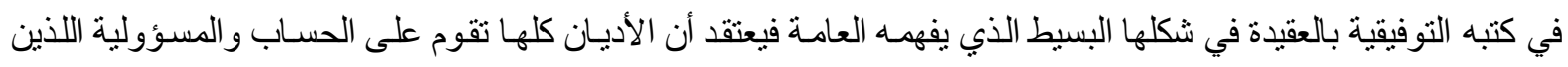

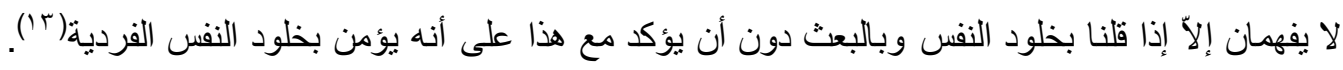

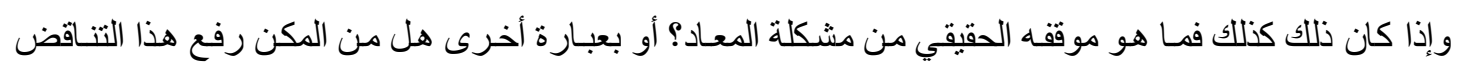

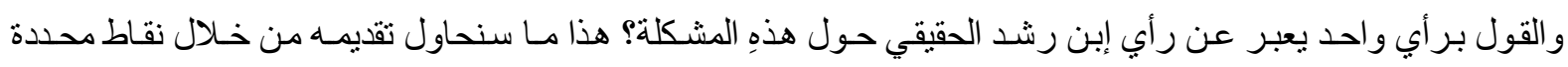

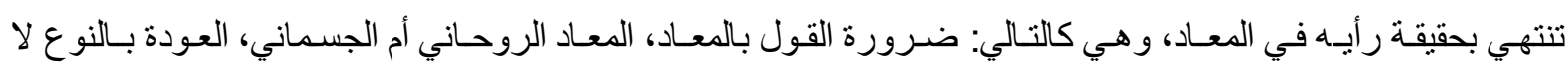
بالعدد، ثم نعرض لخلاصة رأيه: 


\section{أ- ضرورة القول بالمعاد:}

عندما نتصفح كتب إبـن رشــ الحجاجيـة (تهافت التهافتـ فصـل المقـالـ الكثـف عـن منــاهج الأدلـة) فإنتـا لا يخامرنا شك في أن ابن رشد كان يعتقا:

أولاً: بحياة أخرى وراء هذهِ الحياة، تعيش فيها النفس عيشة أبدية خالدة لا تفسد.

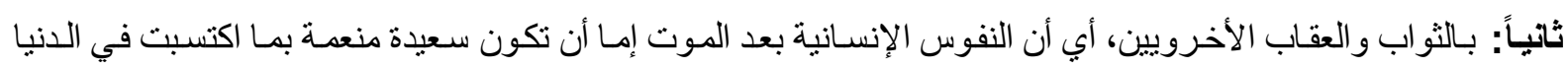

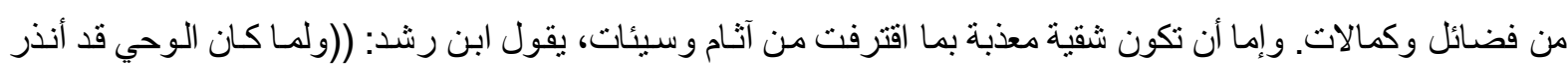

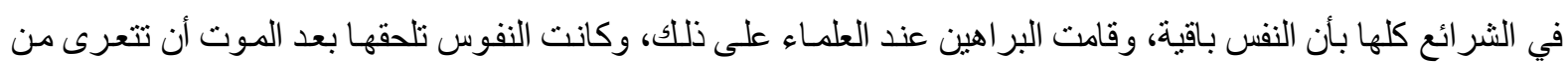

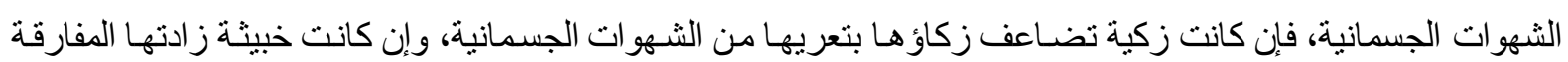

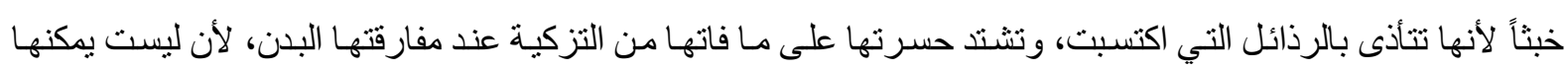

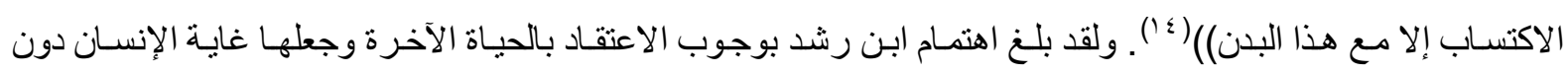

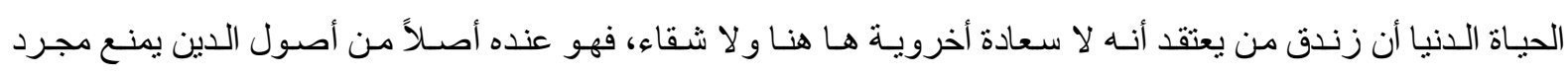

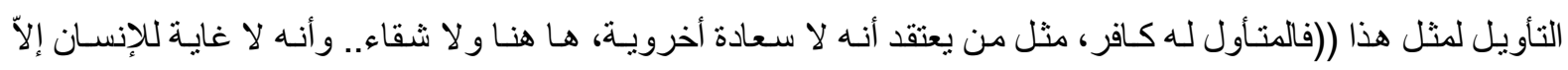

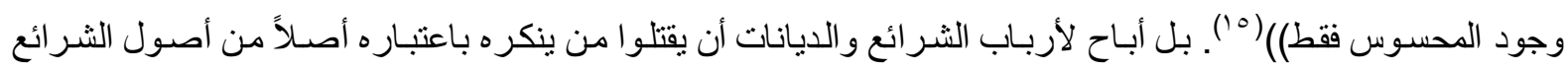
وقاعدة من قو اعد العقل.

وقد يكون إصـرار إبن رشد على القول بـالخلود قائماً على دليل العنايـة كمـا يقوم على التسليم بوجود غائيسة في

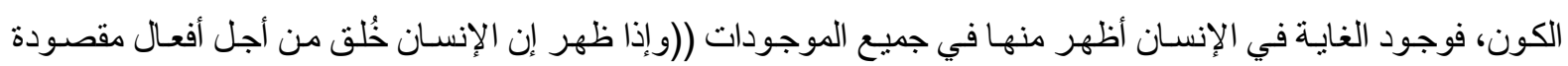

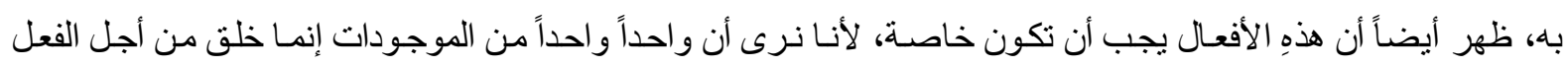

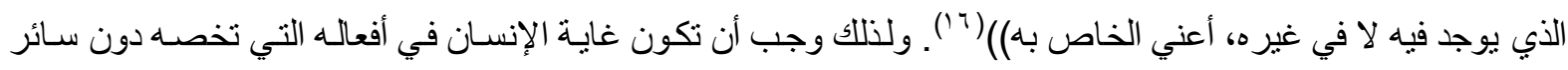
الحيوان و هذهِ هي أفعال النفس الناطقة.

ومن هنـا نرى أن غايـة الإنسـان بمـا هو إنسـان ليست مجرد التمتع باللذات في هذهِ الحياة الدنيا و إنمـا كانت لـهـ

ميزته الخاصة ومقوماته الذاتية التي تميزه عن سـائر الموجودات ونلك أن كل موجود لـه فعل يخصـه وغايـة يسعى إليها

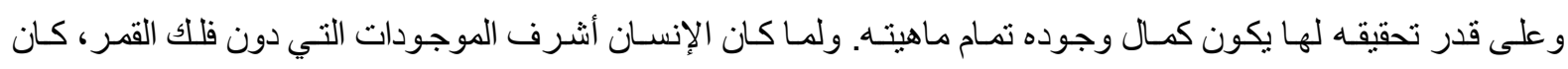

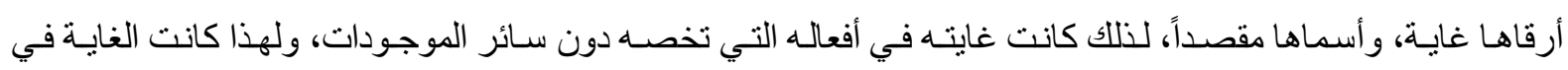

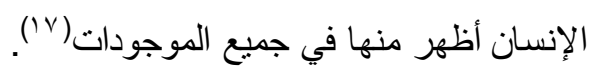

ومن أقوى ما يستدل به إبن رشد على بقاء النفس قوله تعالى (الله يتوفى الأنفس حبن موتها و التي لم تمت فيلا

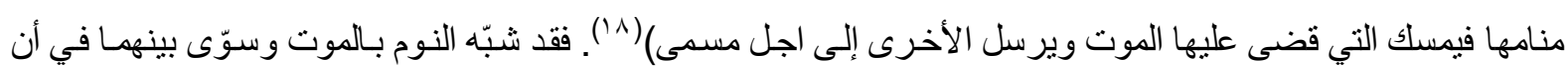

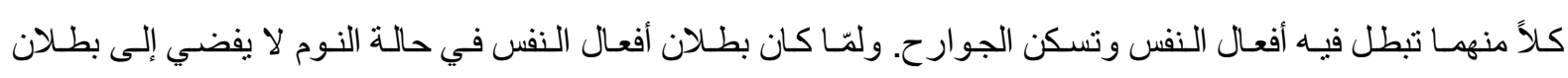
النفس ذاتها، بل مع هذا تظل موجودة متحققة، فقد وجب أن يكون هذا أيضـاً شـأنها في الموت لـون لاتحساد أجزاء التشبيه فيهــا.

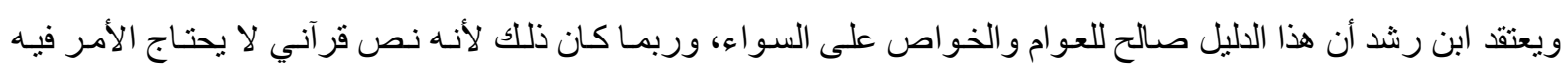
إلى تأو يل و إنما يؤخذ على ظاهره و هذا نصيب الجمهور، ثم هو مع ذلك يستند في معنـاه على مقدمات عقلية تجعله أيضـاً من نصيب الخواص(9) (19). 
نستنتج من ذللك أن بطلان البدن الذي هو آلـة النفس لا يبطل وجود النفس ذاتها، كمـا أن بطلان فعل الصـانع من

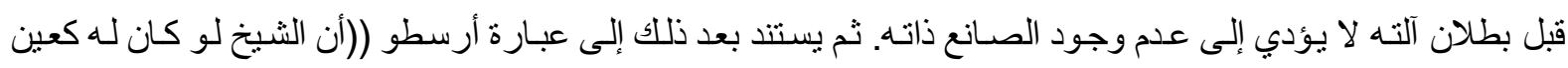

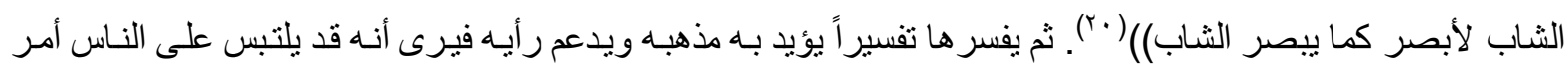

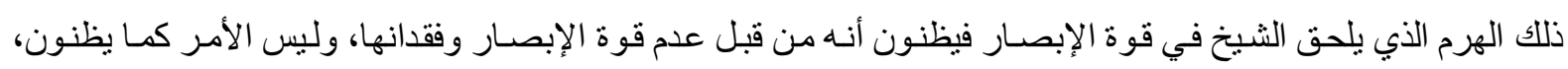

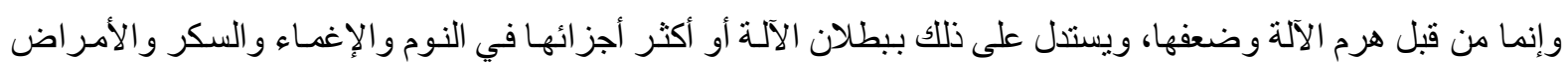
التي تبطل فيها إدراكات الحواس، فإنه لا يشك أن القوى ليست في هذِ الأحوال كاملة (r).

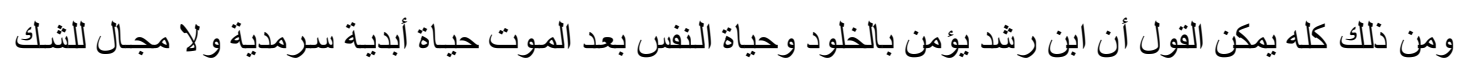

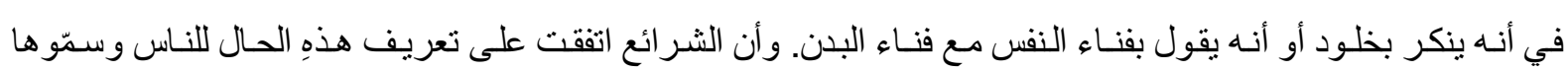
السعادة الأخيرة أو الثقاء الأخير.

\section{المعاد جسيهاني أم روحاني:}

و إذا كانت الشرائع عند ابن رشد قد اتفقت في القول بالمعاد، فإنها اختلفت في تمثيل الأحوال التي تكون لأنفس

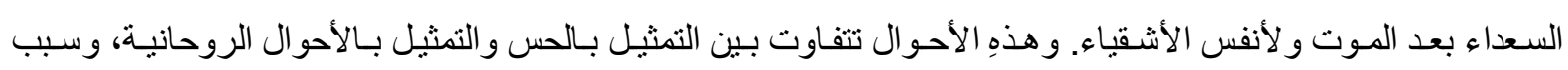
التمثيل بالحس أن ((أصحاب الشرائع أدركوا من هذهِ الأعمال بـالوحي مـا لم يدركها أولئك الذين مثلورا بـالوجود الروحساني.

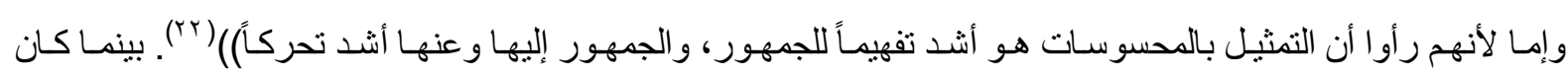

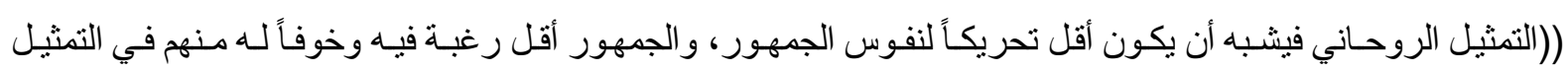

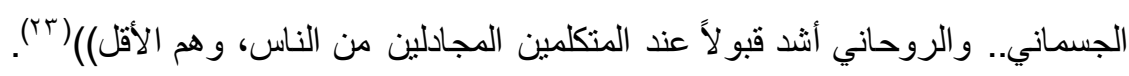
من هنـا كان هنـاك ثنات فرق اختلفت في فهم التمثيل الذي جـاء في الإسـلام ((فرقـة رأت أن ذللك الوجود هو

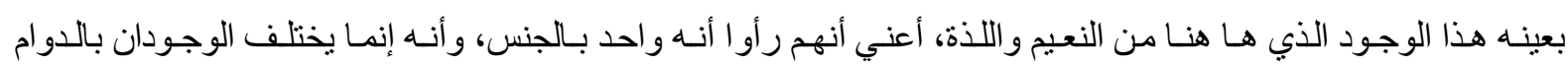
والانقطاع، أعني أن ذلك دائم، وهذا منقطع. وطائفه رأت أن الوجود متباين. وهذهِ انقسمت:

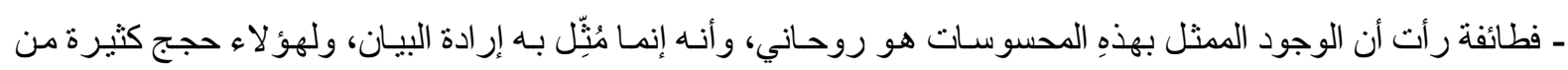
الشريعة مشهورة، فلا معنى لتعديدها.

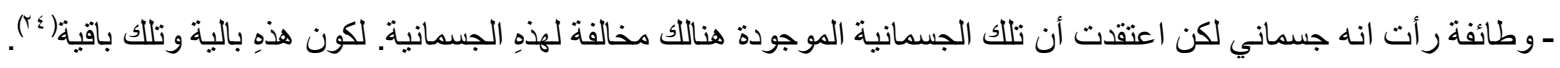
ويرى ابن رشد أن هذا الر أي الأخير يُعد لائقاً بـالخو اص. وسبب ذلك أنه يقوم على أمور ليس فيها خـلاف عند

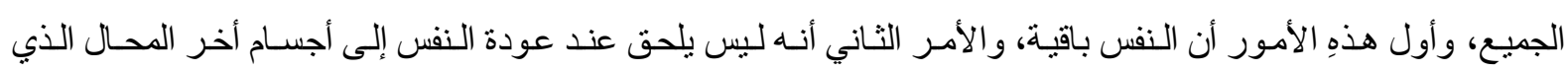

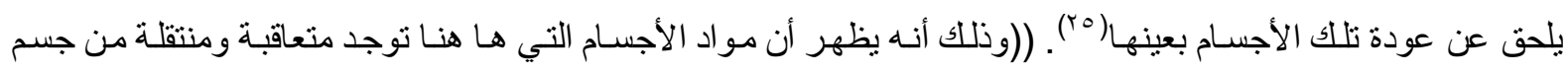

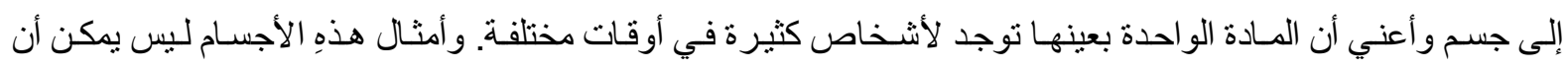

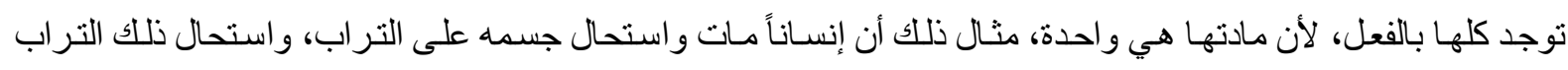

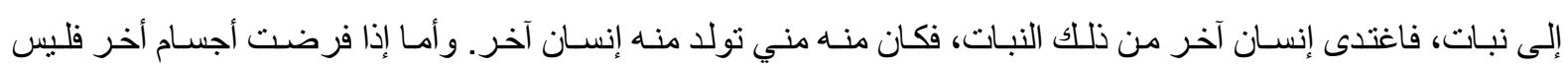

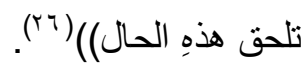

فـالعودة إذن لأجسـام غيـر هذهِ الأجسـام الموجـودة في الدنيا، طالمـا أن لكل جسم هويـة معينـة وطبيعـة ثابتــة

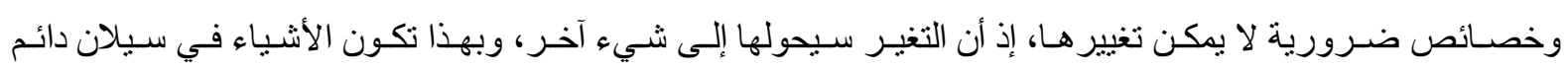

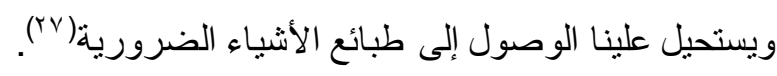




\section{العودة بالنوع لا بالعدد:}

بـالر غم من إقرار ابن رشـد بالمعـاد الجسماني إلا أنسه يرى أن الأجسام التي تعود هـي أمثال هذهِ الأجسـام التي

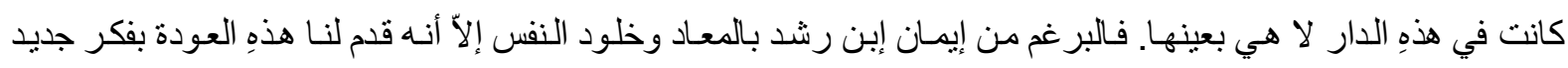

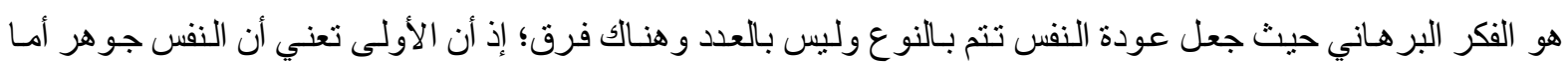

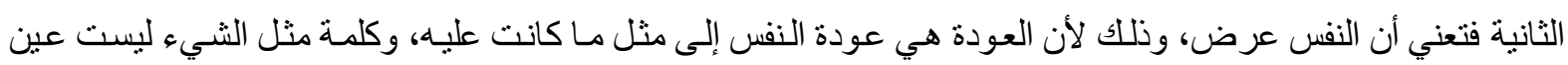
الثـيء، فالمثل يعني التشـابه لكن العين تعني الذات، ولذلك فقد ذهب إبن رشد إلى أن الأشياء العائدة هي أمثال الأشـياء

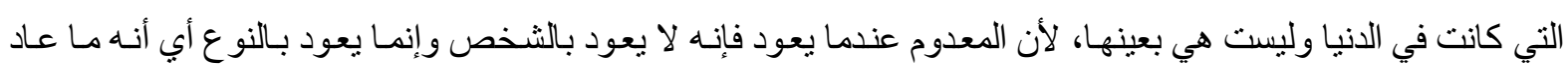

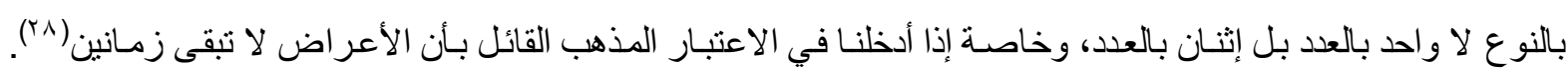

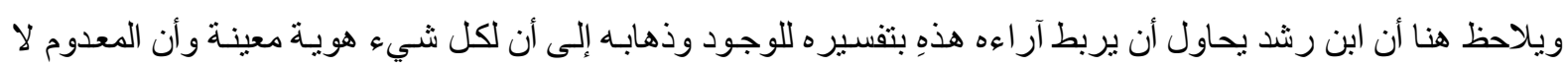

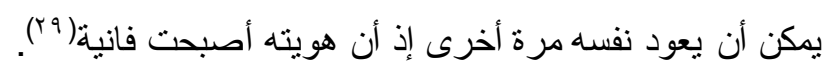

\section{خلاصة رأيه في مسألة المعاد:}

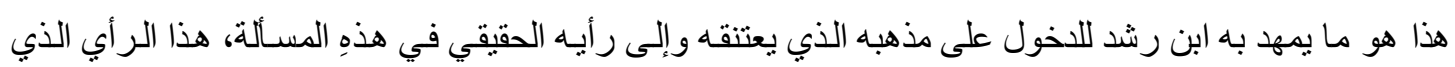

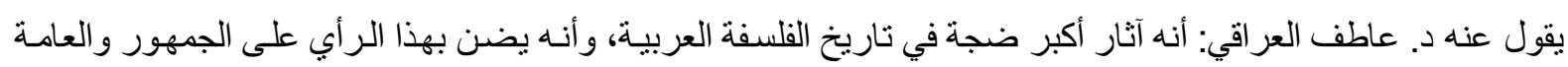

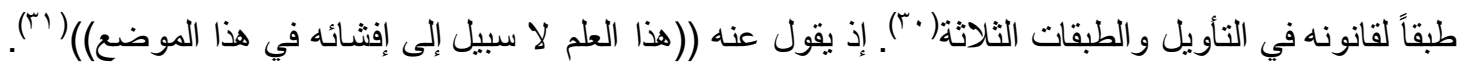
حيث يذهب إبن رشد إلى القول بنفس واحدة كلية تنقسم بالعرض وليس بالذات، فالمنقسم بالذات هو الجسم مثناً

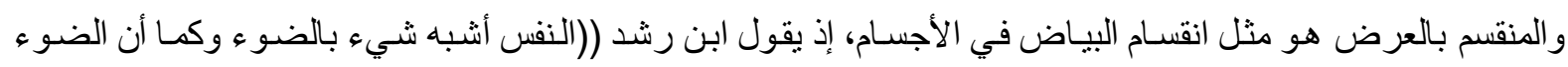

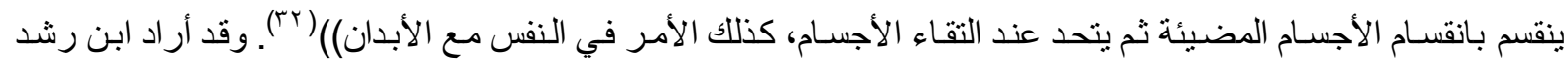

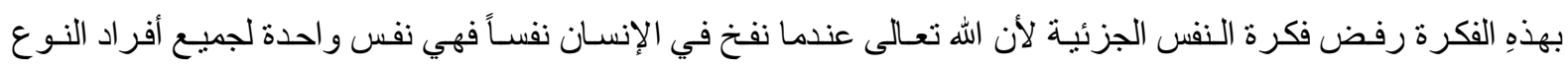

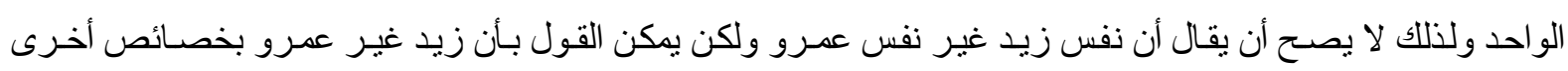

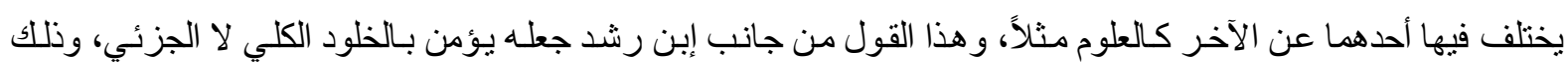

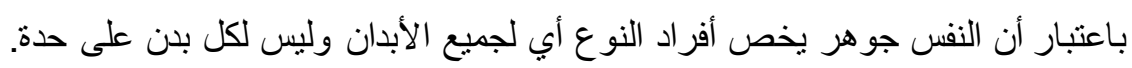
اعتقاد ابن رشد في خلود النفس الكلية، جعله يرفض فكرة الحشر الجسماني، لأنه في حالـة العودة بالبدن يصبح

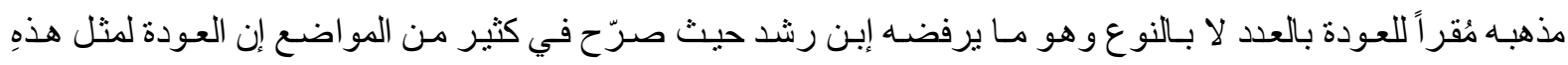

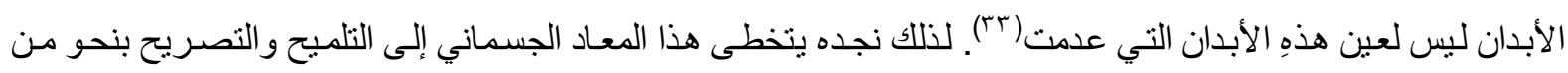

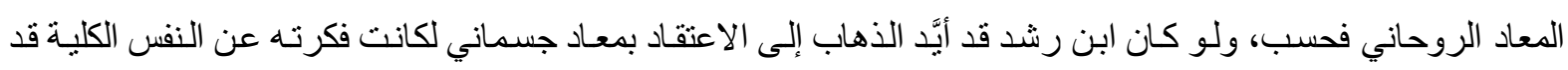
هُمت تماماً. وما يدلل على ذهاب ابن رشد إلى القول بالمعاد الروحاني هو اعتقاده بـأن الأرواح ستعاد في الدار الآخرة

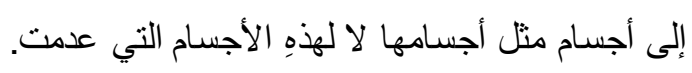

أما ما يبرر تصريحه بالجزاء الجسماني في بعض كتبه، فإن هذا التصريح مردّه تمثيل الجزاء جسمانياً بالنسبة

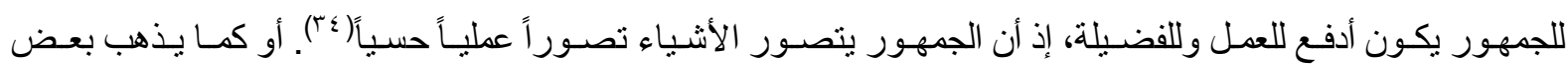

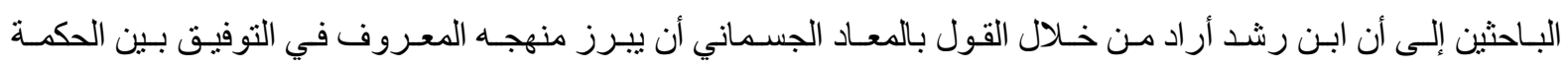

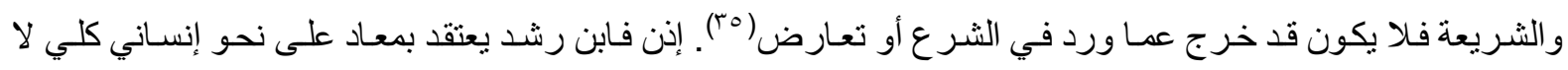

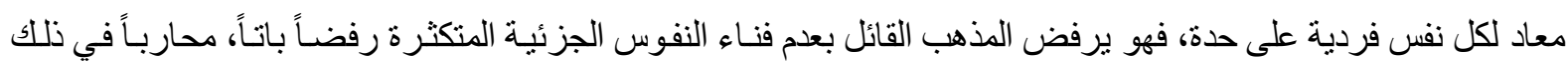




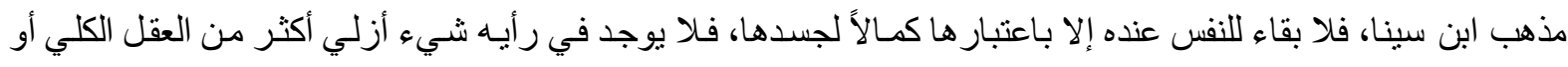

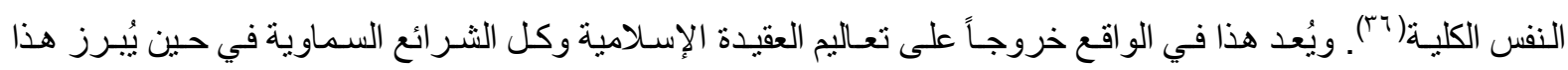

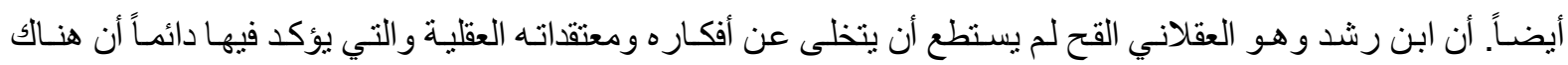

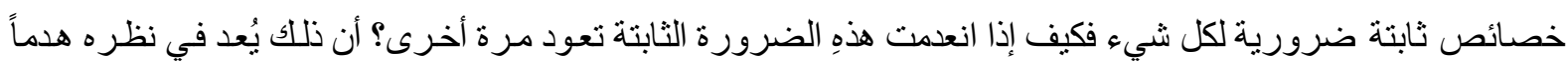

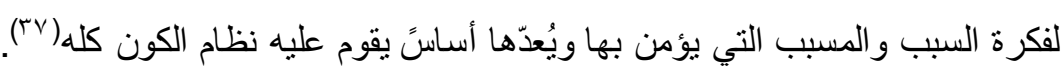

\section{نتائج البحث}

1 - أن الفلاسفة المسلمين بـالأعم الأغلب قـالوا بالمعـاد الروحساني تأسيسًا على مقدماتهم الممهدة للوصـول إلى ذلك

الموقف وتللك القناعة، ومنها:

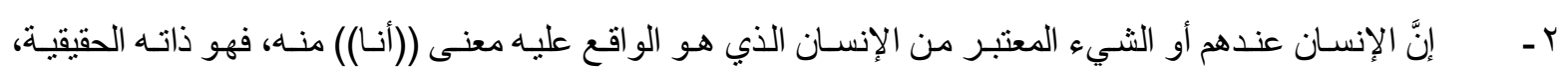

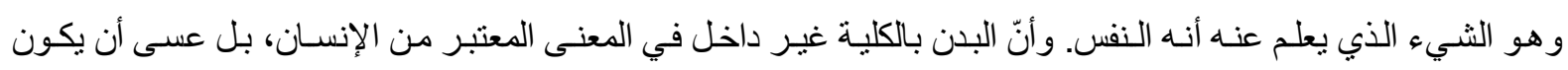

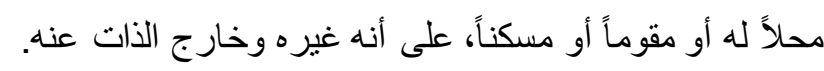

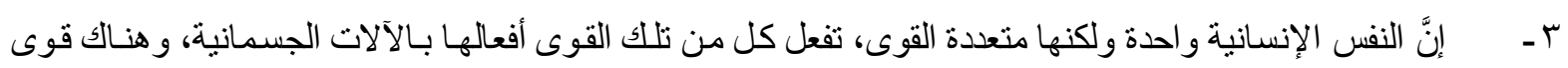

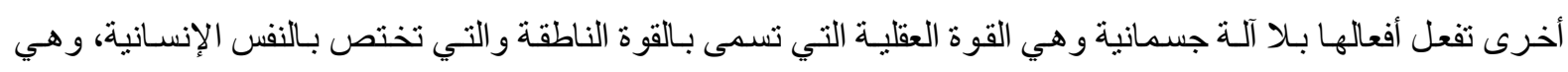
أفضل القوى النفسانية على الإطلاق.

ع - غالباً ما تمسكك فلاسفة الإسلام بالصورة الظاهرية لتعريفات النفس سواء مـا كان منها أفلاطونيـاً أم أرسطياً، إلاًّ

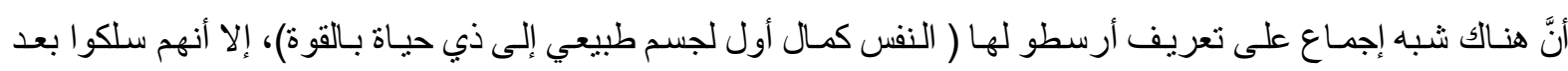
ذللك سلوكاً دالاً على استقلالهم في الر أي، فنجد الفارابي ينتهي إلى موقف مباين لأرسطو حين أكد أن النفس على الحقيقة

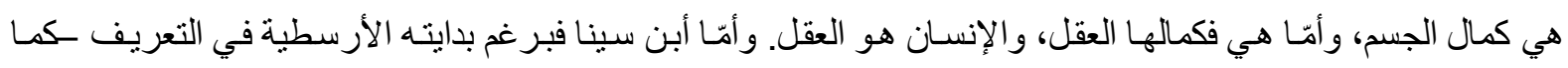

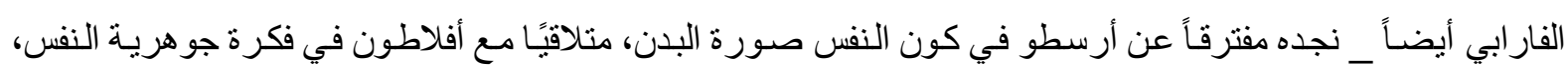

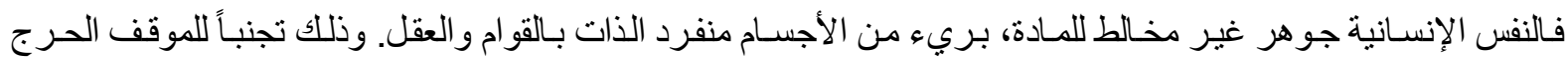

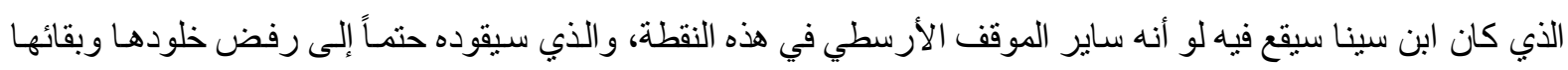

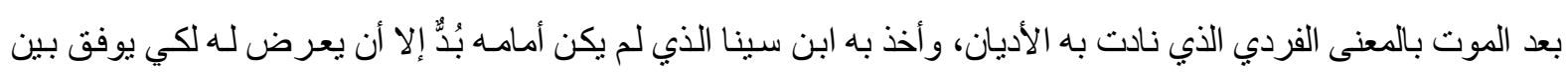

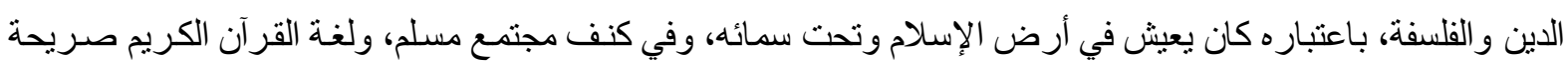

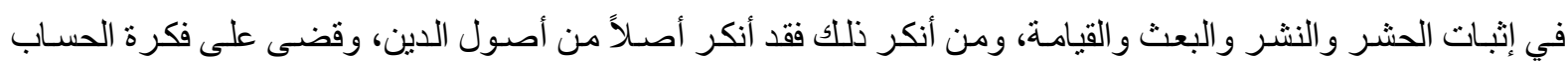

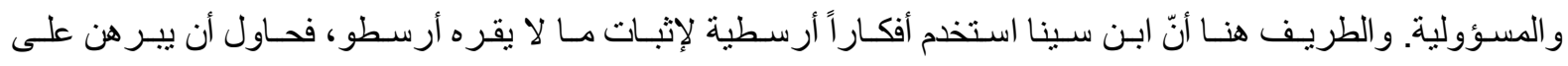

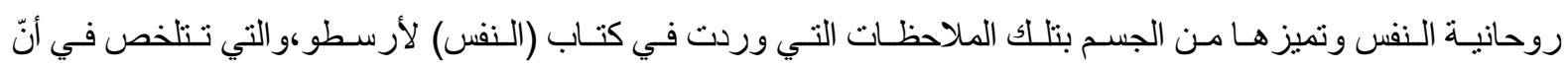

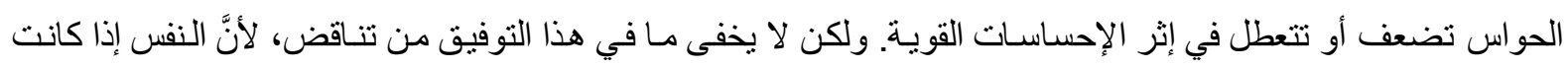

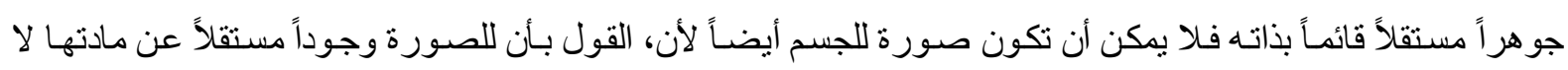
يتفق مع المنطق السليه.

ه - إن النفس عند هؤلاء الفلاسفة جوهر روحاني،غير جسم و لا جسماني،لأن الجوهر الذي تحل فيه الصور العقلية و الكلية جو هر روحاني غير موصوف بصفات الأجسام، وهو الذي نسميه النفس الناطقة التي يدرك بهانيا الإنسـان الموجود

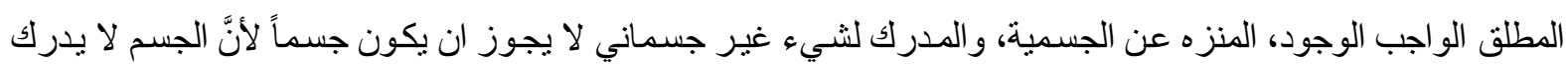


7 - - أن ابن رشد وبنـاءً على مقدماتـه الخاصـة فقد انتهى إلىى أنّ المعـاد على نحو إنسـاني كلي، لا معساد لكل نفس فردية على حدة، فلا يوجد في رأيه شيء أزلي أكثر من العقل الكلي أو النفس الكلية.

الهواهش :

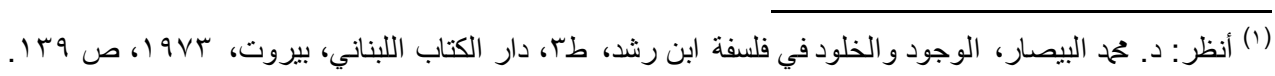

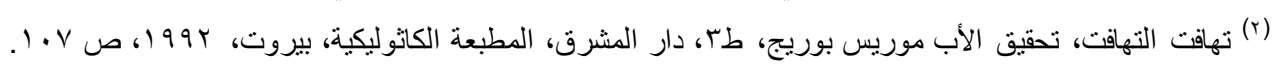

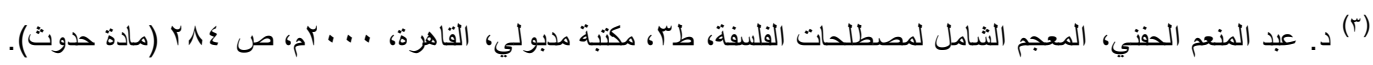

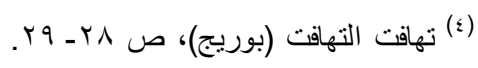

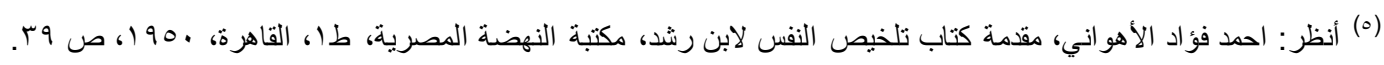

$$
\begin{aligned}
& \text { (1) تهافت التهافت (بوريج)، ص } 9 \text { (1). } \\
& \text { أيضاً، ص OVY (v) }
\end{aligned}
$$

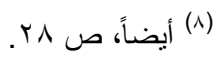

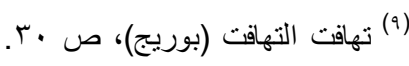

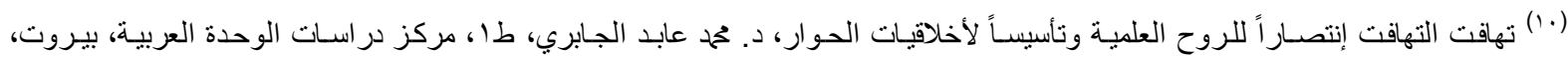

1991 ص ص اله

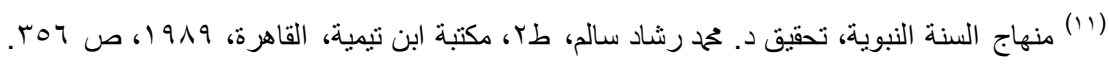

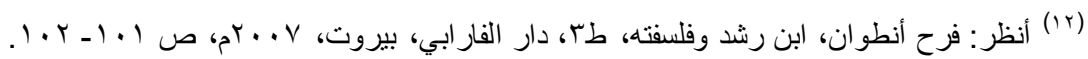

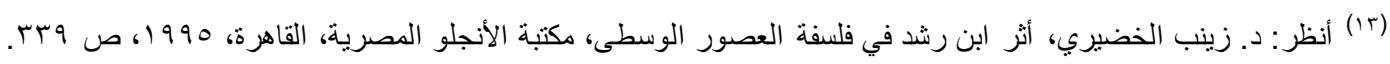

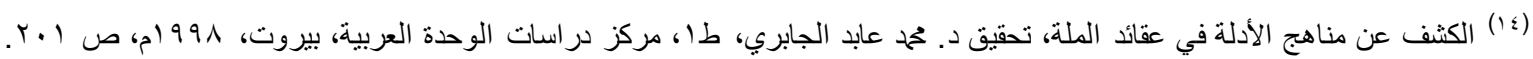

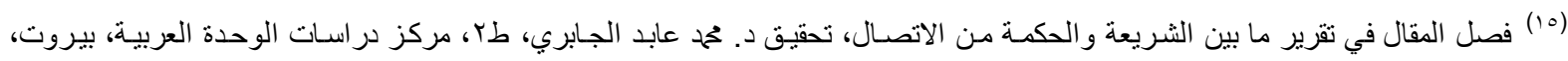

$11 \cdot 0.1999$

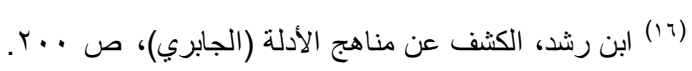

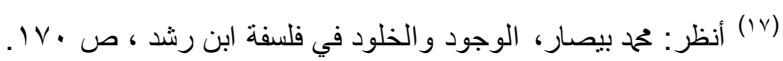

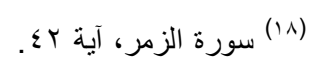

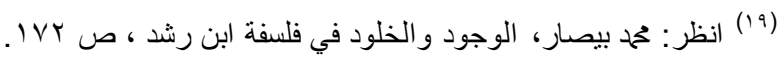

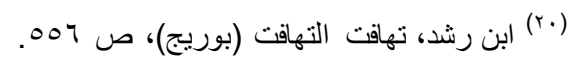

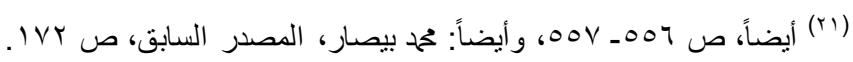

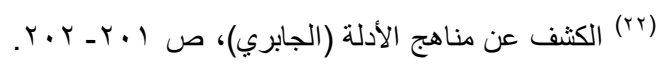

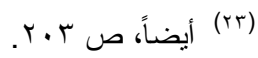

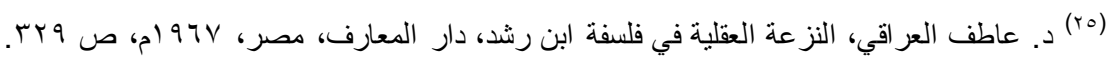

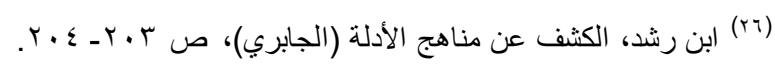

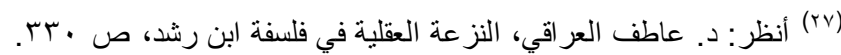

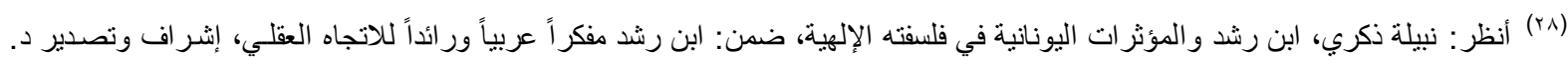

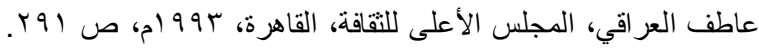

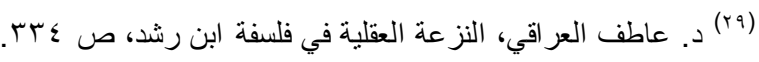

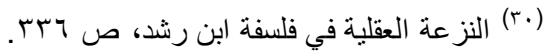

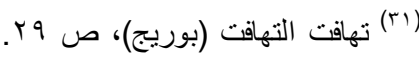

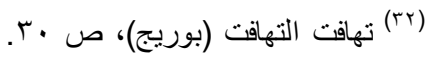

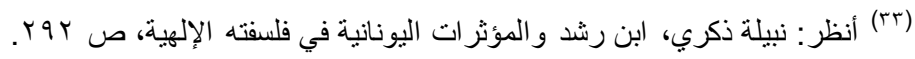




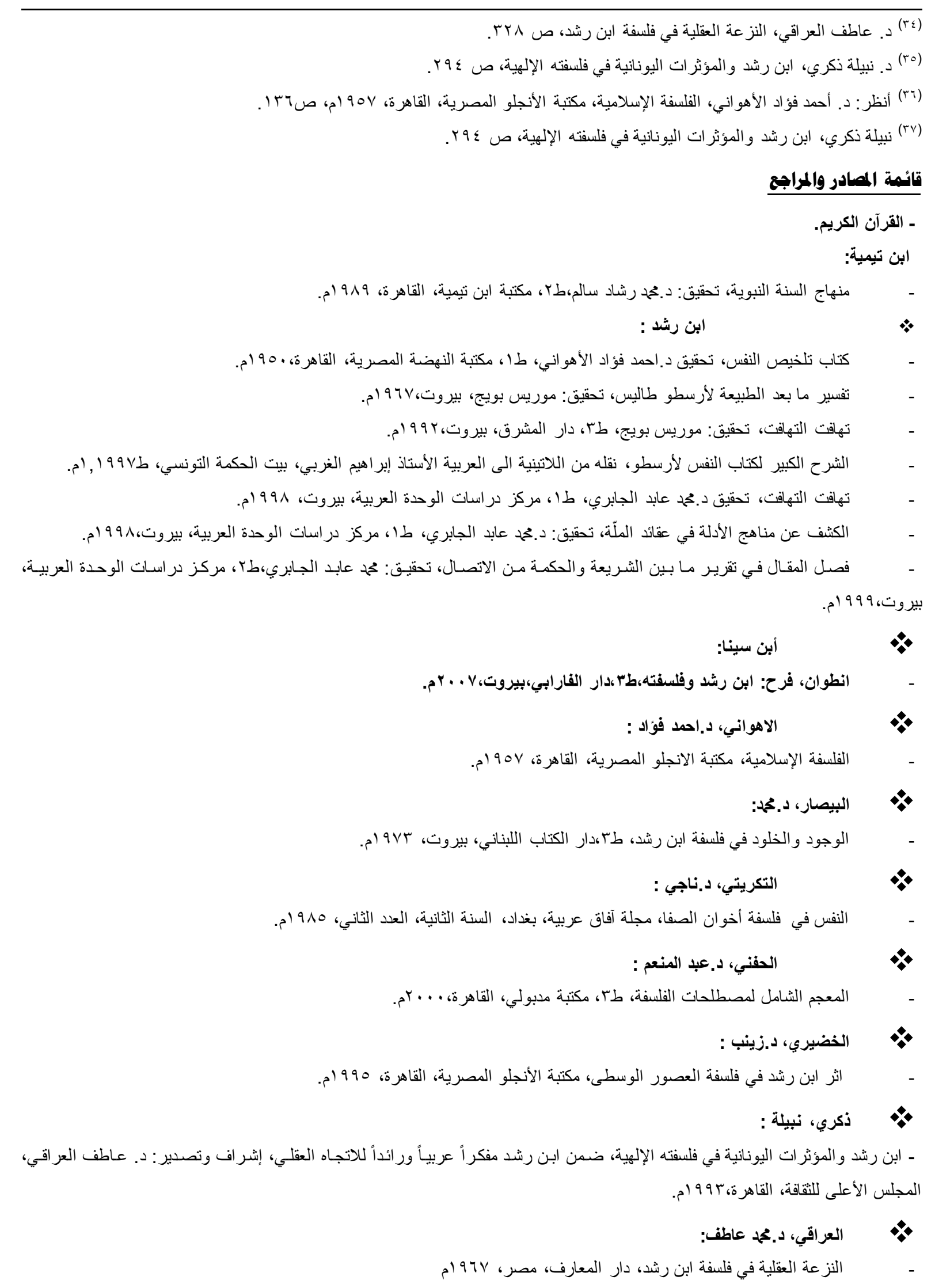

